\title{
Pharmacokinetics, Pharmacodynamics, and Safety of Single-Dose Rivaroxaban in Chronic Hemodialysis
}

\author{
Clapton Dias $^{\mathrm{a}}$ Kenneth Todd Moore ${ }^{\mathrm{a}}$ Joe Murphy ${ }^{\mathrm{a}}$ Jay Ariyawansa ${ }^{\mathrm{a}}$ \\ William Smith $^{b}$ Roger M. Mills ${ }^{a}$ Matthew R. Weir ${ }^{c}$ \\ a Janssen Research \& Development, LLC, Raritan, N.J., ${ }^{b}$ Volunteer Research Group, University of Tennessee Medical \\ Center, Knoxville, Tenn., and 'Division of Nephrology, Department of Medicine, University of Maryland School of \\ Medicine, Baltimore, Md., USA
}

\section{Key Words}

Anticoagulant · Factor Xa inhibitor · Rivaroxaban ·

End-stage renal disease - Hemodialysis . Pharmacokinetics . Pharmacodynamics

\begin{abstract}
Background: This study aimed to characterize the singledose pharmacokinetic (PK) and pharmacodynamic (PD) profile of rivaroxaban $15 \mathrm{mg}$ administered before and after dialysis in subjects with end-stage renal disease (ESRD), and to compare this profile in subjects with ESRD to that in healthy control subjects (creatinine clearance $\geq 80 \mathrm{ml} / \mathrm{min}$ ). Methods: This was an open-label, single-dose, single-center, parallel-group study of rivaroxaban in ESRD subjects who had been clinically stable on maintenance hemodialysis for $\geq 3$ months. In 8 subjects with ESRD, a 15-mg dose of rivaroxaban was administered $2 \pm 0.5 \mathrm{~h}$ before a hemodialysis session and repeated 7-14 days later at $3 \mathrm{~h}$ after a 4-h hemodialysis session. Eight healthy control subjects, matched for age, sex, and body mass index, received one 15-mg rivaroxaban dose. Results: Compared to healthy subjects, area under the rivaroxaban plasma concentration versus time curve
\end{abstract}

(AUC) increased by $56 \%$ following post-dialysis administration. Assuming similar bioavailability between groups, this reflects an approximate 35\% decrease in overall drug clearance in ESRD subjects. Pre-dialysis dosing resulted in only $5 \%$ lowering of AUC versus post-dialysis dosing, confirming the minimal impact of dialysis on the PK of rivaroxaban. PD effects, as assessed by change in prothrombin time, percent factor Xa inhibition, and anti-Xa activity, were generally concordant with observed changes in plasma PK. Conclusions: Changes in PK and PD parameters in chronic dialysis patients were generally comparable to changes observed previously in patients with moderate-to-severe renal impairment who were not undergoing dialysis, and support use of a 15-mg dose in this patient population. 02016 The Author(s)

Published by S. Karger AG, Basel

\section{Introduction}

Rivaroxaban (JNJ 39039039, BAY 59-7939, XARELTO $^{\circledR}$ ) is a potent and highly selective oral direct factor Xa (FXa) inhibitor $[1,2]$. FXa plays a central role in the prothrombinase complex that catalyzes the conver-

\begin{tabular}{ll}
\hline KARGER & $\begin{array}{l}\text { ( } 2016 \text { The Author(s) } \\
\text { Published by S. Karger AG, Basel } \\
\text { 0250-8095/16/0434-0229 } \$ 39.50 / 0\end{array}$ \\
E-Mail karger@karger.com & $\begin{array}{l}\text { This article is licensed under the Creative Commons Attribution- } \\
\text { www.karger.com/ajn }\end{array}$ \\
& $\begin{array}{l}\text { NonCommercial-NoDerivatives 4.0 International License (CC BY- } \\
\text { NC-ND) (http://www.karger.com/Services/OpenAccessLicense). } \\
\text { Usage and distribution for commercial purposes as well as any dis- } \\
\text { tribution of modified material requires written permission. }\end{array}$
\end{tabular}

Kenneth Todd Moore, MS Janssen Scientific Affairs, LLC 1000 US Highway 202

Raritan, NJ 08869 (USA)

E-Mail tmoore17@its.jnj.com 
sion of prothrombin to thrombin. Rivaroxaban has been approved for multiple indications worldwide. In the United States, the Food and Drug Administration approved rivaroxaban in November 2011 to reduce the risk of stroke and systemic embolism in patients with nonvalvular atrial fibrillation, given as a 20 -mg once-daily dose in patients with an estimated creatinine clearance $\left(\mathrm{CL}_{\mathrm{CR}}\right)>50 \mathrm{ml} / \mathrm{min}$ and as a $15-\mathrm{mg}$ once-daily dose for patients with an estimated $\mathrm{CL}_{\mathrm{CR}}$ between 15 and $50 \mathrm{ml} / \mathrm{min}$ (Cockcroft-Gault formula [3]) [4]. The current US labeling recommends that physicians avoid the use of rivaroxaban in patients with end-stage renal disease (ESRD), defined by a $\mathrm{CL}_{\mathrm{CR}}<15 \mathrm{ml} / \mathrm{min}$ [4]. This recommendation reflected a lack of data at the time of the new drug application and the potential for a higher rivaroxaban exposure in this patient population.

In order to elucidate the pharmacology of rivaroxaban in patients with ESRD who were undergoing maintenance hemodialysis, a clinical trial to specifically assess the pharmacokinetic (PK) and pharmacodynamic (PD) profile of rivaroxaban in this unique population was conducted. This open-label, single-dose, single-center, parallel-group study evaluated the use of rivaroxaban in subjects with ESRD who were clinically stable on maintenance hemodialysis for at least 3 months. The 2 primary objectives of this study were (1) to characterize the single-dose $\mathrm{PK}$ and $\mathrm{PD}$ of rivaroxaban administered as a 15-mg dose, both once before and once after dialysis, in subjects with ESRD, and (2) to compare this PK and PD profile in subjects with ESRD to that in healthy control subjects with $\mathrm{CL}_{\mathrm{CR}} \geq 80 \mathrm{ml} / \mathrm{min}$. Additional secondary objectives included assessment of (1) the fraction of a rivaroxaban dose that is removed via hemodialysis, (2) the single-dose PDs of rivaroxaban in subjects with ESRD, and (3) the safety and tolerability of rivaroxaban in subjects with ESRD.

\section{Materials and Methods}

\section{Study Design}

A total of 16 men and women $\geq 18$ years of age, with body mass index (BMI) between 18 and $38 \mathrm{~kg} / \mathrm{m}^{2}$, inclusive, and a body weight of not less than $50 \mathrm{~kg}$ were recruited, including 8 subjects with ESRD (Group A) requiring maintenance hemodialysis 3 times weekly for at least 3 months before screening and 8 healthy matched control subjects (Group B) who had $\mathrm{CL}_{\mathrm{CR}} \geq 80 \mathrm{ml} / \mathrm{min}$ and no evidence of renal disease. For subjects enrolled in Group B, $\mathrm{CL}_{\mathrm{CR}}$ values were estimated using the Cockcroft-Gault equation [3] based on 2 separate serum creatinine measurements obtained during the screening period. The mean of these 2 estimated $\mathrm{CL}_{\mathrm{CR}}$ values was used to confirm eligibility. For the purposes of this study, renal function (defined by a $\mathrm{CL}_{\mathrm{CR}}$ value) was not formally evaluated for patients with ESRD in Group A; however, these patients were classified on the basis of 24-hour urine volume and residual renal function. Patients in Group A were classified as anuric if they had no residual renal function and a 24-hour urine volume of $<50 \mathrm{ml} /$ day; oligo-anuric if they had minimal residual renal function and produced $50-250 \mathrm{ml}$ of urine per day; and not oligo-anuric if they had ESRD and produced $>250 \mathrm{ml}$ of urine per day. For subjects in Group A who produced $>50 \mathrm{ml} /$ day of urine, a blood sample was drawn following the 24 -hour urine collection time frame, serum creatinine levels were measured, and $\mathrm{CL}_{\mathrm{CR}}$ values were estimated using the Cockcroft-Gault equation [3], similar to Group B. To balance the distribution of potential covariates in the ESRD subjects and healthy subjects, group matching was applied to Group B to ensure similarity with respect to sex, age ( \pm 10 years), and BMI $( \pm 20 \%)$ to subjects in Group A.

Subjects receiving hemodialysis were in stable physical condition, consistent with ESRD, were free of concomitant clinically significant hepatic or cardiac disease, and had not had any recent hospitalizations. Subjects were determined to have clinically stable ESRD based on the investigator's judgment using findings from the screening physical examination, medical history, vital signs, 12-lead electrocardiogram, and clinical laboratory tests performed within 3 weeks of the first administration of rivaroxaban. In addition, they were judged suitable for "tight (low) heparinization" during a standard 4-hour hemodialysis session.

High flux hemodialysis was performed using Gambro ${ }^{\circledR}$ (Lakewood, Colo., USA) dialysis machines (flow rate, $600 \mathrm{ml} / \mathrm{min}$ ) with Polyflux ${ }^{\circledR}$ Revaclear dialyzers (Gambro, Phoenix Model, Model No. 6023006700), using a new dialyzer each time. Dialysis followed a "tight (low) heparinization" schedule using unfractionated heparin (UFH); 500 units (U) as an intravenous bolus immediately prior to the start of dialysis followed by an infusion of $500 \mathrm{U} / \mathrm{h}$ for $3 \mathrm{~h}$, at which time the infusion was terminated (total of 2,000 U UFH). Additional heparin during dialysis was allowed if deemed appropriate by the investigator.

The study included a 21-day screening period followed by 2 treatment periods for Group A and 1 treatment period for Group B (fig. 1). For Group A (ESRD subjects), Period 1 consisted of a single, 15-mg oral dose of rivaroxaban administered $2 \pm 0.5 \mathrm{~h}$ before the start of a 4-hour hemodialysis session (pre-dialysis), with PK and PD sampling prior to, during, and after the dialysis session. Period 1 was followed by a 7 - to 14 -day washout period to allow for complete elimination of rivaroxaban; this timeframe was determined based on a period of 5 times the half-life of rivaroxaban. Upon returning for Period 2, Group A subjects received a single, 15-mg oral rivaroxaban dose $3 \mathrm{~h}$ after the completion of a 4-h hemodialysis session (post-dialysis), with pre- and post-dose PK and PD samples taken. For Group B (healthy matched control subjects), treatment consisted of a single period (Period 1) in which subjects received a 15-mg oral dose of rivaroxaban with pre- and post-dose PK and PD samples taken. All rivaroxaban doses were administered with standard meals of similar composition and caloric content. Serial blood samples were collected from each subject prior to and for $72 \mathrm{~h}$ following drug administration for the measurement of rivaroxaban plasma concentrations during treatment Periods 1 and 2 for Group A and treatment Period 1 for Group B. On day 1 of Period 1, a 6-ml venous blood sample was taken from subjects in both groups together with the pre-dose PK blood sample for the determination of the fraction unbound $\left(f_{u}\right)$ of 
Group A

Subjects with ESRD

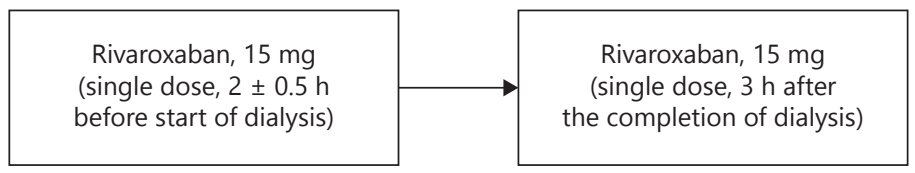

Group B

Subjects with $\mathrm{CL}_{\mathrm{CR}} \geq 80 \mathrm{ml} / \mathrm{min}$

(healthy matched control subjects)

Rivaroxaban, $15 \mathrm{mg}$

(single dose)

Fig. 1. Study design.

rivaroxaban. An additional post-dialysis blood sample was drawn for $\mathrm{f}_{\mathrm{u}}$ immediately upon completion of the dialysis procedure from subjects in Group A. Rivaroxaban concentrations were measured in urine from ESRD subjects in Group A who produced urine, from all subjects in Group B, and in dialysate fluid (Group A only). Analyses of rivaroxaban in plasma, urine, and dialysate were performed via high-performance liquid chromatography with tandem mass spectrometry (MS/MS) detection; as a measure of interassay precision, the coefficient of variation $(\mathrm{CV})$ ranged from 1.93 to $3.87 \%$ in plasma, $3.63-4.58 \%$ in urine, and $1.19-18.6 \%$ in dialysate. The bioanalytical methods for rivaroxaban in plasma and urine had a validated calibration range of $0.50-50.0 \mathrm{ng} / \mathrm{ml}$ [5].

From the plasma, urine, and dialysate data, the following key non-compartmental PK parameters were determined for each group: maximum plasma concentration $\left(\mathrm{C}_{\max }\right)$, time of $\mathrm{C}_{\max }\left(\mathrm{t}_{\max }\right)$, area under the plasma concentration-time curve from time 0 to time of the last observed quantifiable concentration $\left(\mathrm{AUC}_{\text {last }}\right)$, area under the plasma concentration-time curve from time 0 to infinite time $\left(\mathrm{AUC}_{\infty}\right)$, apparent total clearance of drug after extravascular administration $(\mathrm{CL} / \mathrm{F})$, apparent volume of distribution based on the terminal phase after extravascular administration $(\mathrm{Vd} / \mathrm{F})$, and elimination half-life $\left(t_{1 / 2}\right)$. Additional PK parameters were determined based on plasma, urine, and dialysate concentration data.

$\mathrm{PD}$ effects were evaluated using serial prothrombin time (PT; Neoplastin Plus ${ }^{\circledR}$ reagent), FXa inhibition, and anti-FXa (with rivaroxaban calibrators) activity by a central laboratory. PT assays were performed on the STA-R Evolution ${ }^{\circledR}$ coagulation analyzer (Diagnostica Stago, Asnieres-Sur-Seine, France); for intra-assay precision, the CV ranged from 0.7 to $1.7 \%$, and for interassay precision, the $\mathrm{CV}$ ranged from 1.4 to $1.7 \%$. FXa inhibition was determined using a colorimetric assay using S-2765 (Haemochrom, Germany) as the chromogenic substrate; for intra-assay precision, the CV ranged from 1.46 to $5.13 \%$ and for interassay precision, the
CV ranged from 1.36 to $3.23 \%$. Anti-FXa activity was determined using a Technochrom anti-Xa Kit (Technoclon GmbH, Vienna, Austria); for intra-assay precision, the CV ranged from 0.77 to $1.92 \%$, while for interassay precision, the CV ranged from 1.71 to $4.44 \%$. PD measurements were obtained for each subject in Group A during both treatment periods and for Group B during the single treatment period, prior to and for up to $72 \mathrm{~h}$ following the administration of rivaroxaban. The AUC for the PD parameter-time curve from 0 to $72 \mathrm{~h}$ (area under the effect curve (AUEC) for geometric means) and maximum effect ( $\mathrm{E}_{\max }$; using absolute and percent change from baseline values) for each of the PD markers were calculated by treatment period for each subject group.

Safety and tolerability were evaluated throughout the study. This study was sponsored by Janssen Research \& Development, LLC, registered at ClinicalTrials.gov (NCT02289703) on November 10, 2014, and approved by the independent institutional review board at the study site in accordance with the Declaration of Helsinki and consistent with good clinical practices. All subjects gave written informed consent for their participation.

\section{Statistical Analyses}

Sample Size

Based on prior studies, the intersubject CV ranged from 27 to $29 \%$ for PK parameters (AUCs and $\mathrm{C}_{\max }$ ) and $27-43 \%$ for PD parameters (AUC and $\mathrm{E}_{\max }$ for PT, FXa inhibition, and anti-FXa). Assuming the maximum estimated $\mathrm{CV}$, a sample size of $8 \mathrm{ESRD}$ subjects and 8 healthy matched controls would be sufficient for the point estimates of the ratio of mean $\mathrm{PK}$ and $\mathrm{PD}$ parameter of each treatment period in the ESRD group versus the healthy matched controls to fall within $77.4-129.0 \%$ and $68.4-146.0 \%$, respectively, of their true values with $90 \%$ confidence.

Based on prior studies, the estimated intra-subject CV for the PK parameters ranged from 14 to $16 \%$, and the estimated intra- 
Table 1. Demographic and baseline characteristics (safety analysis set)

\begin{tabular}{|c|c|c|c|}
\hline & $\begin{array}{l}\text { ESRD subjects } \\
(\mathrm{n}=8)\end{array}$ & $\begin{array}{l}\text { Normal renal function } \\
\left(\mathrm{CL}_{\mathrm{CR}} \geq 80 \mathrm{ml} / \mathrm{min}\right) \\
(\mathrm{n}=8)\end{array}$ & $\begin{array}{l}\text { Total } \\
(\mathrm{n}=16)\end{array}$ \\
\hline \multicolumn{4}{|l|}{ Age, years } \\
\hline Mean (SD) & $46.4(12.9)$ & $49.3(6.5)$ & $47.8(10.0)$ \\
\hline \multicolumn{4}{|l|}{ Sex, n (\%) } \\
\hline Male & $8(100)$ & $8(100)$ & $16(100)$ \\
\hline \multicolumn{4}{|l|}{ Race, n (\%) } \\
\hline White & $3(38)$ & $7(88)$ & $10(63)$ \\
\hline Black or African American & $5(63)$ & $1(13)$ & $6(38)$ \\
\hline \multicolumn{4}{|l|}{ Baseline BMI, $\mathrm{kg} / \mathrm{m}^{2}$} \\
\hline Mean (SD) & $31.5(5.2)$ & $30.0(1.9)$ & $30.8(3.9)$ \\
\hline \multicolumn{4}{|l|}{ Baseline $\mathrm{CL}_{\mathrm{CR}}, \mathrm{ml} / \mathrm{min}^{\mathrm{a}}$} \\
\hline $\mathrm{n}$ & 3 & 8 & - \\
\hline Mean (SD) & $2.67(3.06)$ & $132.75(26.04)$ & - \\
\hline Median (range) & $2.00(0.0-6.0)$ & $128.23(100.9-175.2)$ & - \\
\hline
\end{tabular}

subject $\mathrm{CV}$ for the PD parameters ranged from 37 to $41 \%$ for rivaroxaban in subjects with normal renal function and mild or moderate renal impairment. Assuming the intra-subject CVs are the same as the maximum estimated CV of $16 \%$ for the PK parameters and $41 \%$ for the PD parameters for rivaroxaban, a sample size of 8 subjects who completed all of the treatment periods in the ESRD group would be sufficient for the point estimate of the ratio of mean $\mathrm{PK}$ and $\mathrm{PD}$ parameters of rivaroxaban, following single-dose administration of a 15 -mg dose of rivaroxaban pre- and post-hemodialysis, to fall within $85.8-116.6 \%$ and $67.8-147.6 \%$, respectively, of its true values with $90 \%$ confidence.

PK and PD Parameter Analyses

The primary PK parameters of interest (AUCs and $\mathrm{C}_{\max }$ ) and $P D$ parameters of interest (AUEC and $\mathrm{E}_{\max }$ for PT and FXa inhibition) were log-transformed.

Mixed-effects models that included renal function group/ treatment period as a fixed effect and subject as a random effect were used to estimate the least squares means (LSMs) and inter-/ intra-subject variances. Using the estimated LSMs and inter-/intra-subject variances, the point estimate and 90\% CIs for the difference in means on a log scale were constructed. The limits of the CIs were retransformed using anti-logarithms to obtain $90 \%$ CIs for the ratios of the mean PK and PD parameters of the test (ESRD subjects; Periods 1 and 2) to reference (healthy matched control subjects) between group comparisons, and test to reference within the ESRD group pre- and post-dialysis comparison. $\mathrm{PK}$ and PD parameters were also summarized by descriptive statistics. The following software was used in the calculation of PK and PD data for this study: Analyst version 1.6.2 and PPD Assist LIMS version 5. Statistical evaluations were performed using the SAS version 9.2 software package (SAS Institute, Cary, N.C., USA).

\section{Results}

Sixteen subjects were enrolled and completed the study. Table 1 shows the clinical and demographic characteristics of the subjects in both groups. All subjects were male, and the groups were well matched for age and BMI.

Tables 2 and 3 show rivaroxaban PK data from Group A, both before and after dialysis, and from Group B. Rivaroxaban was highly protein-bound in both study groups (table 2). Rivaroxaban plasma concentrations (mean + $\mathrm{SD}$ ) as a function of time following drug administration are shown in figure 2 as a semi-logarithmic plot. Renal function had little impact on rivaroxaban $\mathrm{C}_{\max }$. As compared to healthy subjects, Group A subjects when dosed $3 \mathrm{~h}$ after dialysis had an increased systemic exposure as measured by AUC of approximately 56\%, reflecting a $35 \%$ decrease in overall clearance. This assumes that the bioavailability of rivaroxaban is similar between ESRD subjects and healthy volunteers. Administration of rivaroxaban prior to a 4-hour dialysis session resulted in only a 5\% lowering of plasma AUC compared to post-dialysis administration. The ratio of active transport to passive filtration of unchanged rivaroxaban observed in this study was approximately $3: 1(40: 14 \mathrm{ml} / \mathrm{min})$.

Table 4 shows the impact of dialysis on rivaroxaban $\mathrm{PK}$ in Group A. Both $\mathrm{C}_{\max }$ and AUC were slightly lower when rivaroxaban was administered pre-dialysis as compared to post-dialysis, with geometric mean ratios of 77 and $95 \%$, respectively. 
Table 2. Arithmetic mean (SD) plasma PK parameters following a single 15-mg dose of rivaroxaban in subjects with normal renal function and ESRD

\begin{tabular}{|c|c|c|c|}
\hline \multirow[t]{2}{*}{ Parameter } & \multirow{2}{*}{$\begin{array}{l}\text { Normal renal function } \\
\left(\mathrm{CL}_{\mathrm{CR}} \geq 80 \mathrm{ml} / \mathrm{min} ; \mathrm{n}=8\right)\end{array}$} & \multicolumn{2}{|l|}{ ESRD } \\
\hline & & pre-dialysis $^{\mathrm{a}}(\mathrm{n}=8)$ & post-dialysis $^{\mathrm{b}}(\mathrm{n}=8)$ \\
\hline $\mathrm{C}_{\max }, \mathrm{ng} / \mathrm{ml}$ & $210(30.8)$ & $194(47.2)$ & $247(40.2)$ \\
\hline$t_{\max }, h^{c}$ & $3.0(0.5-6.0)$ & $3.0(1.0-6.0)$ & $2.0(1.0-4.0)$ \\
\hline $\mathrm{AUC}_{\text {last }}, \mathrm{ng} \cdot \mathrm{h} / \mathrm{ml}$ & $1,848(404)$ & $2,740(613)$ & $2,857(495)$ \\
\hline $\mathrm{AUC}_{\infty}, \mathrm{ng} \cdot \mathrm{h} / \mathrm{ml}$ & $1,879(432)^{\mathrm{d}}$ & $2,770(622)$ & $2,907(500)$ \\
\hline$t_{1 / 2}, h$ & $6.2(1.8)^{\mathrm{d}}$ & $12.2(3.8)$ & $13.2(5.7)$ \\
\hline $\mathrm{Vd} / \mathrm{F}, 1$ & $71.0(8.9)^{\mathrm{d}}$ & $101(39)$ & $101(44)$ \\
\hline $\mathrm{CL} / \mathrm{F}, \mathrm{l} / \mathrm{h}$ & $8.31(1.70)^{\mathrm{d}}$ & $5.69(1.46)$ & $5.34(1.21)$ \\
\hline Protein-bound rivaroxaban, $\%$ c, e & $89(87-93)$ & $86(80-94)$ & \\
\hline
\end{tabular}

\footnotetext{
${ }^{a}$ Pre-dialysis, subjects dosed $2 \mathrm{~h}$ before hemodialysis.

${ }^{\mathrm{b}}$ Post-dialysis, subjects dosed $3 \mathrm{~h}$ after hemodialysis.

${ }^{\mathrm{c}}$ Expressed as median (range).

${ }^{d} \mathrm{n}=7$; healthy subject 220107 was excluded from $\mathrm{AUC}_{(0-\infty)} \mathrm{PK}$ parameter analysis due to variability in the terminal phase ( $\mathrm{r}^{2}$ adjustment $\left.<0.9000\right)$.

e Percentage of rivaroxaban that is protein-bound in pre-dose plasma.
}

Table 3. Rivaroxaban PK parameters: ESRD subjects vs. subjects with normal renal function

\begin{tabular}{|c|c|c|c|c|}
\hline \multirow[t]{2}{*}{ Parameter } & \multirow[t]{2}{*}{$\mathrm{n}$} & \multicolumn{2}{|c|}{ Geometric mean } & \multirow{2}{*}{$\begin{array}{l}\text { Geometric mean ratio } \\
(90 \% \mathrm{CI})\end{array}$} \\
\hline & & ESRD $\left(\right.$ test $\left.^{\mathrm{a}, \mathrm{b}}\right)$ & $\begin{array}{l}\text { normal renal function } \\
\left(\mathrm{CL}_{\mathrm{CR}} \geq 80 \mathrm{ml} / \mathrm{min} \text {; }\right. \\
\left.\text { reference }^{\mathrm{c}}\right)\end{array}$ & \\
\hline \multicolumn{5}{|l|}{ Pre-dialysis } \\
\hline $\mathrm{C}_{\max }, \mathrm{ng} / \mathrm{ml}$ & 8 & 188.91 & 208.03 & $90.81(77.47-106.44)$ \\
\hline $\mathrm{AUC}_{\text {last }}, \mathrm{ng} \cdot \mathrm{h} / \mathrm{ml}$ & 8 & $2,675.86$ & $1,812.99$ & $147.59(122.72-177.5)$ \\
\hline $\mathrm{AUC}_{\infty}, \mathrm{ng} \cdot \mathrm{h} / \mathrm{ml}$ & 8 & $2,704.55$ & $1,839.68^{\mathrm{d}}$ & $147.01(120.6-179.21)$ \\
\hline \multicolumn{5}{|l|}{ Post-dialysis } \\
\hline $\mathrm{C}_{\max }, \mathrm{ng} / \mathrm{ml}$ & 8 & 244.91 & 208.03 & $117.73(100.44-137.99)$ \\
\hline $\mathrm{AUC}_{\text {last }}, \mathrm{ng} \cdot \mathrm{h} / \mathrm{ml}$ & 8 & $2,814.07$ & $1,812.99$ & $155.22(129.06-186.67)$ \\
\hline $\mathrm{AUC}_{\infty}, \mathrm{ng} \cdot \mathrm{h} / \mathrm{ml}$ & 8 & $2,862.10$ & $1,839.68^{d}$ & $155.58(127.63-189.64)$ \\
\hline
\end{tabular}

a Group A (pre-dialysis): ESRD subjects, $15 \mathrm{mg}$ rivaroxaban administered $2 \pm 0.5 \mathrm{~h}$ before hemodialysis session.

${ }^{\mathrm{b}}$ Group A (post-dialysis): ESRD subjects, $15 \mathrm{mg}$ rivaroxaban administered $3 \mathrm{~h}$ after hemodialysis session.

${ }^{c}$ Group B: healthy matched control subjects $\left(\mathrm{CL}_{\mathrm{CR}} \geq 80 \mathrm{ml} / \mathrm{min} ; 15-\mathrm{mg}\right.$ dose of rivaroxaban administered 30 minutes after the start of meal).

${ }^{d} \mathrm{n}=7$; healthy subject 220107 was excluded from $\mathrm{AUC}_{(0-\infty)} \mathrm{PK}$ parameter analysis due to variability in the terminal phase $\left(\mathrm{r}^{2}\right.$ adjustment $\left.<0.9000\right)$.

Figure 3 shows the effect of rivaroxaban on $\mathrm{PT}$ and percent FXa inhibition over time in Group A, pre- and postdialysis, and in Group B. PD changes were generally concordant with the observed changes in plasma $\mathrm{PK}$ and were higher in ESRD subjects compared to healthy subjects.
No bleeding events occurred during the study. Three subjects in Group A experienced 4 adverse events, including 2 episodes of nausea, 1 of gingivitis, and 1 of arteriovenous shunt thrombosis. None of the adverse events were deemed serious by the site investigator. 
Fig. 2. Arithmetic (mean + SD) plasma concentration-time profiles following a single, 15-mg oral dose of rivaroxaban in subjects with normal renal function and ESRD, shown as a semi-logarithmic plot with an inset figure showing a linear plot.

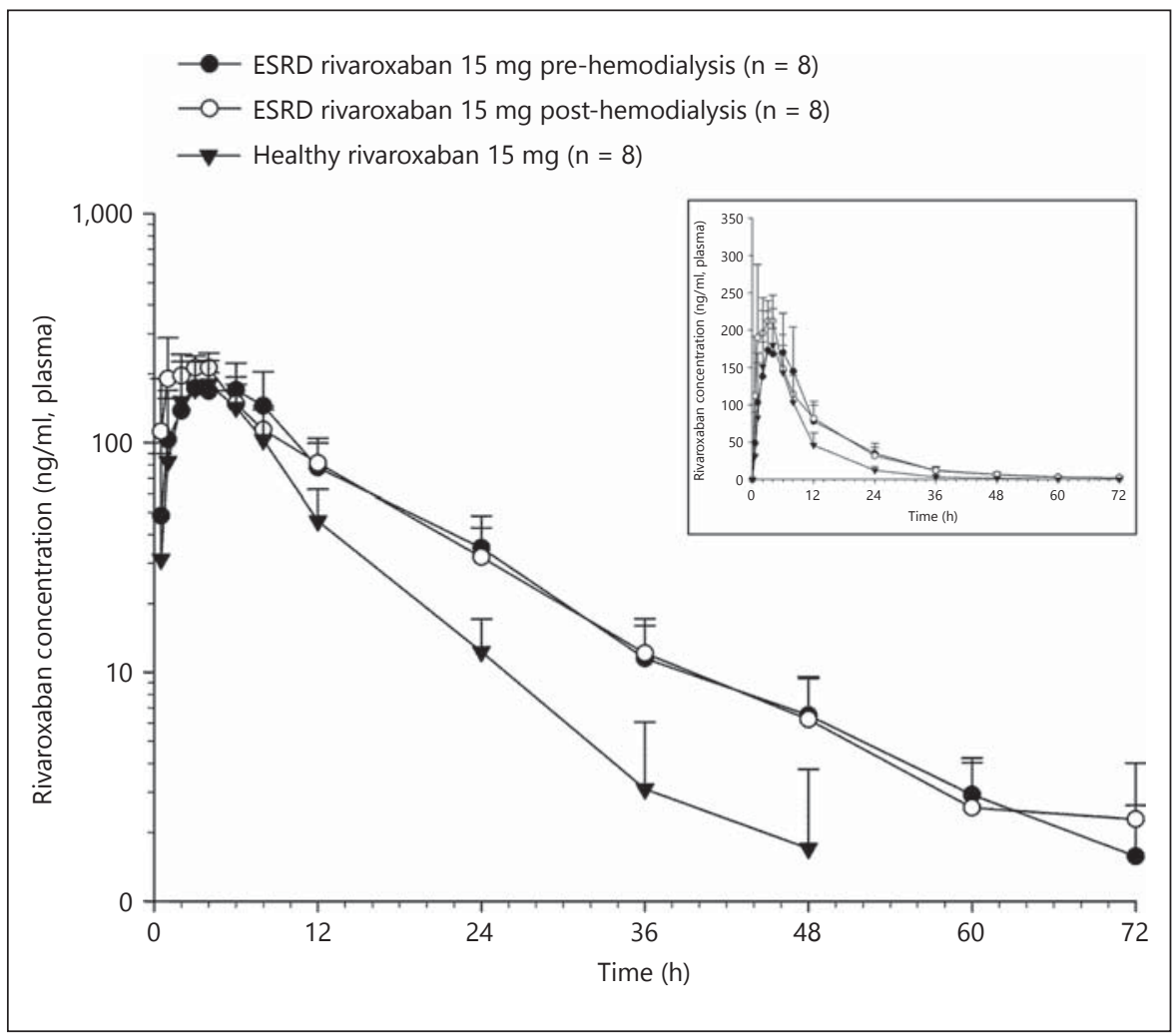

Table 4. Rivaroxaban PK parameters (ESRD pre-dialysis vs. ESRD post-dialysis)

\begin{tabular}{|c|c|c|c|c|}
\hline \multirow[t]{2}{*}{ Parameter } & \multirow[t]{2}{*}{$\mathrm{n}$} & \multicolumn{2}{|l|}{ Geometric mean } & \multirow{2}{*}{$\begin{array}{l}\text { Geometric mean } \\
\text { ratio }(90 \% \mathrm{CI})\end{array}$} \\
\hline & & pre-dialysis (test $\left.{ }^{\mathrm{a}}\right)$ & post-dialysis (reference ${ }^{b}$ ) & \\
\hline $\mathrm{C}_{\max }, \mathrm{ng} / \mathrm{ml}$ & 8 & 188.91 & 244.91 & $77.13(64.17-92.72)$ \\
\hline $\mathrm{AUC}_{\text {last }}, \mathrm{ng} \cdot \mathrm{h} / \mathrm{ml}$ & 8 & $2,675.86$ & $2,814.07$ & $95.09(84.98-106.39)$ \\
\hline $\mathrm{AUC}_{\infty}, \mathrm{ng} \cdot \mathrm{h} / \mathrm{ml}$ & 8 & $2,704.55$ & $2,862.10$ & $94.50(84.16-106.1)$ \\
\hline
\end{tabular}

\section{Discussion}

Our data show that, as compared to healthy control subjects, in ESRD subjects on chronic hemodialysis, the rivaroxaban plasma AUC was increased by approximately $56 \%$ following a single, 15-mg dose of rivaroxaban administered post-dialysis. Assuming similar bioavailability between the 2 groups, this reflects an approximate 35\% decrease in overall clearance due to ESRD and is consistent with the contribution of renal clearance to the overall clearance of rivaroxaban as currently described in the drug package insert $[4,6]$. In addition, rivaroxaban administration prior to a 4-hour hemodialysis session resulted in only a 5\% lowering of plasma AUC as compared to the AUC with post-dialysis dosing, indicating that dialysis has a minimal impact on the PK of rivaroxaban. This is consistent with the generally high protein binding of rivaroxaban observed in the current trial (table 2) and observed previously [4]. PD effects were generally consistent with an increase in rivaroxaban exposure in ESRD subjects compared with healthy subjects. Changes in PT and FXa inhibition followed changes observed in the PK of rivaroxaban. 


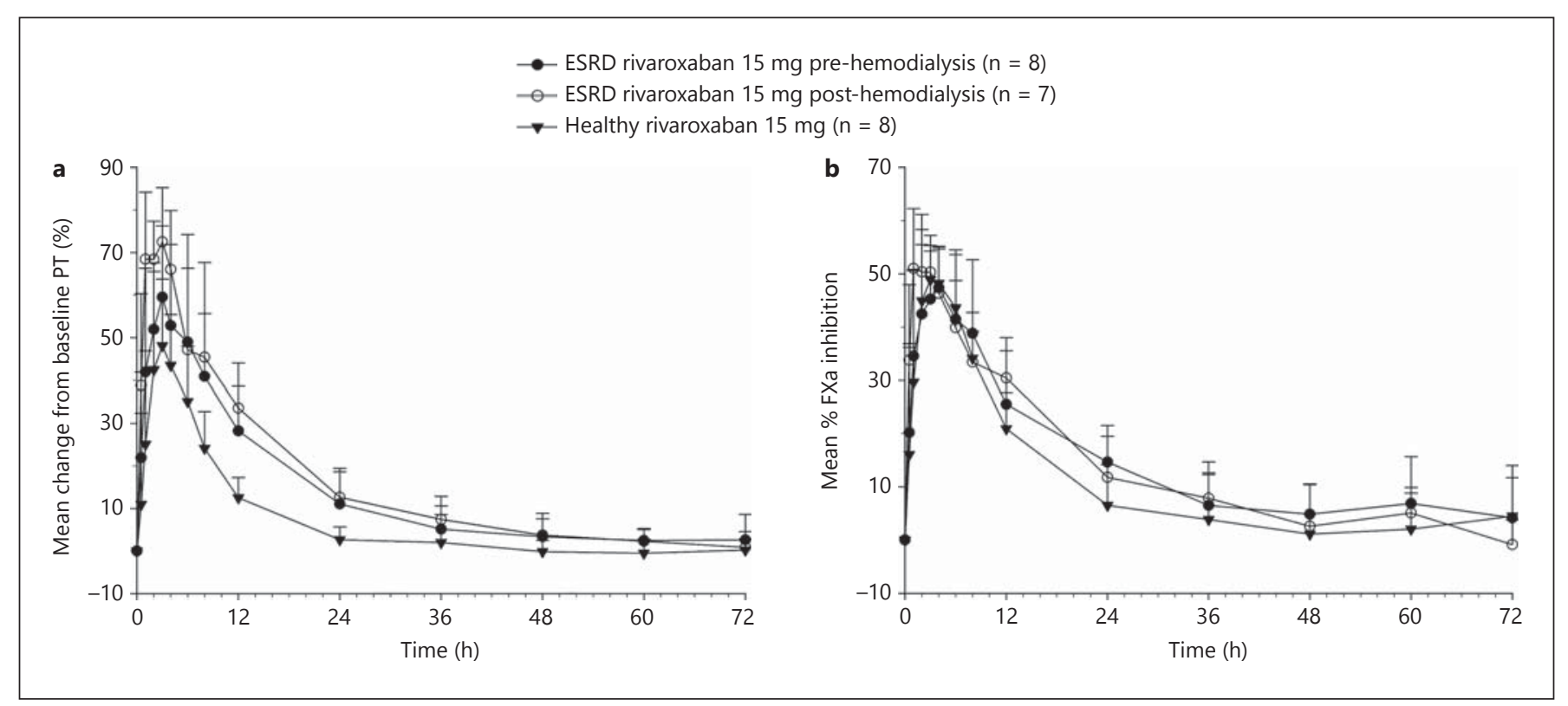

Fig. 3. Arithmetic (mean + SD) PT percent change from baseline profiles (a) and FXa percent inhibition (b) following a single, 15-mg oral dose of rivaroxaban in healthy and ESRD subjects.

The changes in PK and PD parameters found in the current study of chronic dialysis subjects were generally comparable to the PK and PD changes observed previously in patients with moderate-to-severe renal impairment who were not undergoing dialysis [6]. For example, the approximately $56 \%$ increase in systemic exposure (AUC) observed in this study is similar to the increases in exposure previously shown for patients with either moderate renal impairment $(52 \%$ increase in AUC) or severe renal impairment (64\% increase in AUC) [6]. As anticipated, these findings support that filtration-based measures of renal function, for example, the widely used estimating equations for $\mathrm{CL}_{\mathrm{CR}}$ or GFR, may not adequately describe the loss of tubular secretory function (e.g., P-gp and BCRP transport) in patients with chronic kidney disease. This is an important concept; the ratio of active transport to passive filtration of unchanged rivaroxaban observed in this study was approximately $3: 1$, indicating the relative predominance of active renal secretion in elimination of this drug. The decline in active transport function, which is required to clear rivaroxaban, may reach a maximum before there is a complete loss of passive filtration. Thus, as confirmed with our data in patients on chronic hemodialysis, a single $15-\mathrm{mg}$ rivaroxaban dose results in comparable drug exposure for patients with moderate, severe, or ESRD.
This study was subject to a number of potential limitations. First, all subjects were male and the majority of subjects were black; however, gender and ethnicity do not have a clinically relevant impact on the PK of rivaroxaban [4]. Furthermore, the demographics of the population of subjects with ESRD in the current study are in keeping with those of previous studies of other anticoagulants in subjects with ESRD, which also included populations that were predominantly male and black $[7,8]$. The subjects with ESRD in the current study were age-, gender-, and BMI-matched with the control arm; therefore, the relative changes observed in PK parameters should not be affected by these subject-related variables. In addition to these characteristics of the study population, there were certain treatment characteristics that could potentially affect PK outcomes. All subjects underwent a standardized 4-hour hemodialysis session using a pre-specified tight (low) heparin dose regimen; neither the effects of other hemodialysis durations nor different heparin dose regimens on the $\mathrm{PK}$ or $\mathrm{PD}$ of rivaroxaban are known. Finally, rivaroxaban, like all anticoagulants, is associated with a risk of bleeding events, which may be higher in patients with ESRD on hemodialysis due to complicating factors, including other comorbidities, poor platelet function, and the use of other concomitant therapies [9]. The population of subjects with ESRD in this study was small $(\mathrm{n}=8)$; furthermore, 
large-scale randomized trials would be required to fully evaluate the efficacy and safety of rivaroxaban in patients with ESRD on hemodialysis.

Importantly, there are no safety and efficacy data to establish the potential risks and benefits of rivaroxaban in this population. Nonetheless, dosing in special populations (particularly with renal or hepatic impairment) is typically justified based on clinical pharmacology studies with a sound understanding of the PK/PD relationship. Matching exposures to those observed in phase 3 trial populations is a common approach used to justify dose adjustment if the exposure change in a special population is significant.

\section{Conclusions}

Overall, results from this study show that deterioration of renal filtration function from severe to ESRD does not have a significant impact on rivaroxaban PK and PD beyond those changes observed with either moderate or severe renal impairment. These results were determined in a population of otherwise healthy subjects with ESRD undergoing hemodialysis in standard 4-hour sessions, using a "tight (low) heparinization" schedule.

\section{Disclosure Statement}

J.A. is a full-time employee of Janssen Research \& Development, LLC. C.D., K.T.M., J.M., and R.M.M. were full-time employees of Janssen Research \& Development, LLC at the time of manuscript preparation. K.T.M. is a full-time employee of Janssen Scientific Affairs, LLC. W.S. has no conflicts of interest to disclose. M.R.W. served as a scientific advisor to Janssen.

\section{Acknowledgments}

This study was sponsored by Janssen Research \& Development, LLC. Editorial assistance was provided by Ashley O'Dunne, $\mathrm{PhD}$, of MedErgy (Yardley, Pa., USA), and funded by Janssen Scientific Affairs, LLC. The authors would like to thank Angelika Roth and Stephan Schwers (Bayer HealthCare, Assay Technologies) for their assistance with performing PD analyses.

\section{References}

1 Mueck W, Schwers S, Stampfuss J: Rivaroxaban and other novel oral anticoagulants: pharmacokinetics in healthy subjects, specific patient populations and relevance of coagulation monitoring. Thromb J 2013;11:10.

2 Mueck W, Stampfuss J, Kubitza D, Becka M: Clinical pharmacokinetic and pharmacodynamic profile of rivaroxaban. Clin Pharmacokinet 2014;53:1-16.

3 Cockcroft DW, Gault MH: Prediction of creatinine clearance from serum creatinine. Nephron 1976;16:31-41.

4 XARELTO $^{\circledR}$ (rivaroxaban) tablets, for oral use [package insert]. Titusville, Janssen Pharmaceuticals, Inc., 2015.
Rohde G: Determination of rivaroxaban-a novel, oral, direct factor Xa inhibitor-in human plasma by high-performance liquid chromatography-tandem mass spectrometry. J Chromatogr B Analyt Technol Biomed Life Sci 2008;872:43-50.

Kubitza D, Becka M, Mueck W, Halabi A, Maatouk H, Klause N, Lufft V, Wand DD, Philipp T, Bruck H: Effects of renal impairment on the pharmacokinetics, pharmacodynamics and safety of rivaroxaban, an oral, direct factor Xa inhibitor. Br J Clin Pharmacol 2010;70:703-712

Murray PT, Reddy BV, Grossman EJ, et al: A prospective comparison of three argatroban treatment regimens during hemodialysis in end-stage renal disease. Kidney Int 2004;66: 2446-2453.
Wang X, Tirucherai G, Marbury TC, Wang J, Chang M, Zhang D, Song Y, Pursley J, Boyd RA, Frost C: Pharmacokinetics, pharmacodynamics, and safety of apixaban in subjects with end-stage renal disease on hemodialysis. J Clin Pharmacol 2015, Epub ahead of print. Shah M, Avgil Tsadok M, Jackevicius CA, Essebag V, Eisenberg MJ, Rahme E, Humphries $\mathrm{KH}$, Tu JV, Behlouli H, Guo H, Pilote L: Warfarin use and the risk for stroke and bleeding in patients with atrial fibrillation undergoing dialysis. Circulation 2014;129: 1196-1203. 


\section{Erratum}

\section{Nephrology}

In the article by Dias $\mathrm{C}$ et al., entitled 'Pharmacokinetics, pharmacodynamics, and safety of single-dose rivaroxaban in chronic hemodialysis' (Am J Nephrol 2016;43:229_ 236, DOI: 10.1159/000445328), in the paragraph describing adverse events on p. 233, the number of subjects who experienced adverse events should have been given as two rather than three:

'No bleeding events occurred during the study. Two subjects in Group A experienced 4 adverse events, including 2 episodes of nausea, 1 of gingivitis, and 1 of arteriovenous shunt thrombosis.' 